\begin{tabular}{|c|c|c|c|}
\hline$\underbrace{\text { INTERNATIONAL }}_{\text {INESEG }}$ & $\begin{array}{r}\text { International } \\
\text { Res } \\
w w\end{array}$ & $\begin{array}{l}\text { urnal of Health Services, } \\
\text { rch and Policy } \\
\text { rgipark.org.tr/ijhsrp }\end{array}$ & \\
\hline $\begin{array}{l}\text { ENGINEERING, } \\
\text { SCIENCE AND } \\
\text { EDUCATION GROUP }\end{array}$ & e-ISSN: 2602-3482 & DOI:10.23884/ijhsrp.2019.4.2.04 & IJHSRP \\
\hline
\end{tabular}

Research Article

\title{
FRAILTY AMONG THE BENEFICIARIES OF BATUMI ST. CATHERINE NURSING
} HOME

\author{
"Rusudan KHUKHUNAISHVILII ${ }^{\text {iD }, \text { Marina KORIDZE }}{ }^{1}$ iD , Kristine MAKHARADZE ${ }^{1}$ iD, \\ Sophiko TSKVITINIDZE ${ }^{I}$ iD , Marina NAGERVADZE ${ }^{1}$ iD , $\operatorname{Irina}_{\text {NAKASHIDZE }}{ }^{\text {iD }}$, \\ Irakli PARULAVA ${ }^{1}$ iD
}

${ }^{1}$ Department of Biology, Batumi Shota Rustaveli State University, Georgia

"Corresponding author; rusudan.khukhunaishvili@bsu.edu.ge

\begin{abstract}
Frailty is defined as "medical syndrome with multiple causes and contributors that is characterized by diminished strength, endurance, and reduced physiologic function that increases an individual's vulnerability for developing increased dependency and/or death. An assessment of Frailty in various populations, especially in the elderly population, has medical outcomes. The present work deals with the study of frailty in the beneficiaries of Batumi St. Catherine Nursing Home of. In total 70 beneficiaries of both sexes, were over 60 years of age, were investigated. The study was conducted in two years 2016-2017. Frailty phenotypes were assessed within five criteria: weight loss, self-reported exhaustion, weakness, slowness, and low physical activity. The existence of three and more criteria from these listed criteria are assessed as frail phenotype; the existence of one or two criteria - prefrail, and if a person does not have any criteria, it is assessed as robust. $25.7 \%$ of the elder beneficiaries turned out to be frailty phenotype, 12,9\% - prefrail phenotype, $61.4 \%$ - healthy or sustainable. Total frailty phenotype was identified in 18 samples, including 11 women and 7 men. Hard cognitive disorders from the 18 frailty phenotypes were found in only 3 individuals. Among the three most commonly researched populations in the frailty criteria are low physical activity, weakness, and slowness. In the group of people older than 80 years, the syndrome of frailty was higher (35.7\%) than in the group of people older than 60 years. (19\%). The gender difference was not observed. As the research has shown frailty syndrome is revealed in beneficiaries in both investigated groups. It is important to pay special attention to assess frailty syndrome in the nursing community, to be used timely medical, social or other activities.
\end{abstract} Keywords: Frailty, nursing home, beneficiaries, elderly

Received: May 13, $2019 \quad$ Accepted: May 31, 2019

\section{Introduction}

Individuals of the same age may not age at the same rate. Quantitative biomarkers of aging are valuable tools to measure physiological age, assess the extent of 'healthy aging', and potentially predict health span and life span for an individual [1]. Aging is a major risk factor for most chronic diseases and functional impairments. Within a homogeneous age sample, there is a considerable variation in the extent of disease and functional impairment risk, revealing a need for valid biomarkers to aid in characterizing the complex aging processes. [2] Biomarkers are increasingly employed in empirical studies of human populations to understand physiological processes that change with age, diseases whose onset appears linked to age, and the aging process itself [3-5]. There is a lot of attention to studying longevity phenotypic markers. Phenotypic markers are relatively simple and non-invasive, 
although less accurate. Integration of these methods is essential for the complete analysis of healthy aging mechanisms [2].

In recent years, frailty syndrome spread among elderly populations has been actively studied. Frailty has long been considered synonymous with disability and comorbidity, to be highly prevalent in older age and to high risk for falls, hospitalization, and mortality. However, it becomes recognized that frailty may be a distinct clinical syndrome with a biological basis [6].

There are two opinions about the development of frailty: the first - the frailty of the elderly as a phenotype, the genotypically conditioned [7] and the second - the unity of acquired deficiencies developed on the background of polymorbidity [8].

In human populations, frailty may be revealed during different ages. The obtained results of research in age groups of different populations are not universal. According to the data available in scientific publications, frailty is prevalent in older people [9], the probability of syndrome is significantly increased after the age of 80 [10]. There are contradictory data, and some authors believe that the frailty is not an age-dependent process, and often the long-livers are not asthenic [11].

Among current operational definitions of frailty, the criteria proposed by Fried have attracted great scientific interest [12]. Fried and colleagues point out at five basic characteristics of frailty: weight loss, self-reported exhaustion, weakness, slowness, and low physical activity [7].

Thus, frailty can be considered as an adaptive response of the body which is followed by the slowdown in metabolism and the decrease of the action intensity of the body and body system. At the same time, frailty is considered a dynamic process that can be improved or worsened after a certain period of time $[10,13]$. It is noteworthy that the risk of deterioration is higher, followed by incapacitation, hospitalization, and mortality [14].

Hence, it is important to identify the pre-asthenic prefrailty status and persons with a frailty risk group that will enable practitioners to determine further development and management capabilities.

The demographic aging rate is very high in the population of Georgia. In addition, several tens of thousands of older citizens are deprived of permanent residence (forcibly displaced people). Most of these people live in nursing homes. Thus, elderly population research is quite relevant in this direction. Especially in places where the concentration of older people is particularly high, it is important not only to detect and evaluate the phenotypes of frailty syndrome but also to find a resource that an elderly person has in a given case and to direct it to help them [2].

The aim of our research was to study frailty prevalence in the community of nursing homes. The target group was selected because of that the majority of beneficiaries are socially vulnerable people with various health problems.

\section{Materials and methods}

The research was conducted at Batumi St. Catherine nursing home. We have studied 70 beneficiaries from ages 60 to 93. The study was conducted for two years between 2016 and 2017.

In our research, we used a questionnaire (Brief Assessment Protocol Centenarians) modified by Porto University, which was approved in the study of Portuguese centenarian population [15]. The questionnaire includes demographic, social, health, functional, psychological and cognitive aspects. The questionnaire was translated and adapted to the Georgian reality.

The survey was conducted in the form of individual visits and face-to-face with researchers. One or two (seldom three) visits were made with each member of the study group. The study was conducted by the World Medical Association Declaration of Helsinki, Ethical Principles for Medical 
Research Involving Human Subjects. All participants of the research have confirmed the willingness of voluntary participation in the experiment. The inquiry was attended by the representative of the nursing home. The obtained results were processed statistically.

During the survey, 122 beneficiaries lived in a nursing home. Since the target group was composed of people with the age of more than 60,19 of them were excluded at the beginning of the research because of age incompatibility, 33 people did not participate in the study for various reasons: disability, tiredness or lack of desire to participate in the study. Finally, we have studied and analyzed the populations of 70 people of more than 60 years of age.

Identification of phenotypes of frailty syndrome was conducted according to the following criteria and procedures:

Socio-demographic characteristics included assessment and data analysis of age, sex, education, marital status, and living conditions; for determining the cognitive status we applied MMSE (MiniMental State Examination) [16], the questionnaire includes an assessment of cognitive, functional and behavioral disorders. Each component is measured by points (1 to 5); Cognitive status assessment also includes the evaluation of dementia range. Finally, according to cognitive status the study groups were divided into three groups: severe (0-17 points); moderate (18-23 points); mild (24-30 points); ADLs (Activities of Daily Livings) - This criterion assessment is based on the Duke University's Center for Disease and Human Development Research, [17] developed for American Population. The questionnaire was adapted for Georgian populations - taking into consideration the lifestyle and mentality of the population. The questions included daily activities: nutrition, bath taking, walking, personal hygiene protection, etc. Totally seven types of activities were estimated from 0 to 14 points; Morbidity and Medical Treatment - this criterion includes 14 different chronic diseases of cardiovascular, urinary, parenteral and other systems. Due to the high statistics of goiter in the local population, we added this disease to the questionnaire. We also indicated how many medicines a beneficiary daily received; Subjective health - this criterion was assessed based on the subjective response (feeling) of the survey. The questionnaire was divided into two categories: 1) excellent / very good / good; 2) fair / poor.

Finally, we have identified frailty phenotype by five criteria defined by Freid and coauthors: weight loss, self-reported exhaustion, weakness, slowness, and low physical activity. Three and more criteria from the listed criteria were assessed as frail; The existence of one or two criteria indicates frailty on the previous period and is defined as prefrail phenotype, which represents a high-risk group and is highly likely to progress. And if a person does not have any criteria, was assessed as robust [7].

\section{Results and Discussion}

We analyzed the findings of the research conducted due to the above-listed procedures and criteria in the study population, as well according to gender. A total of 70 samples including 43 (61.4\%) female and $27(38,6 \%)$ male. Since there is evidence that the probability of frailty detection significantly increases after the age of 80 [10], we also analyzed the frailty distribution by age groups. We separated two age groups: first from 60 to 80 years; second - more than 80 years old. The first table represents social-demographic and health survey results (Tab. 1).

Marital Status: Only three women from the study group have never been married; The majority of the study group are widows, including 21 females (30\%) and 9 males (12,9\%); 15,7\% of respondents were divorced, from them - seven female and four male. At the moment of the survey, $37,1 \%$ of the respondents were married ( 12 female 14 male). 
Among the first age groups (60-80) were 42 samples, among them 26 females $(61,9 \%), 16$ males (38.1\%) were married, only two women were never married (4,8\%), widow $-21,4 \%$, divorced $-19,7 \%$, living with a partner - $0 \%$. It is noteworthy that the percentage of widows among the beneficiaries of the nursing home is twice more than men widows, while the married beneficiaries almost half in amount and almost equal in both sexes (26,2\% female and $24 \%$ male), while there live more woman in the nursing home than man.

The second age group (80+) included 28 samples, among them 17 (60,7\%) females and 11 $(39,3 \%)$ mails. The percentage of widows in this age group is twice high compared to the first age group that is logical since this group is more elder. From the whole research group, married people were 17,9\% (including the majority of men). One woman never was in marriage. All the respondents rejected the fact of co-existence with an informal (unmarried partner) partner. It seems that the reason is local traditions and elderly mentality.

Table 1. Results of Socio-demographic and health characteristics of the sample

\begin{tabular}{|c|c|c|c|c|c|c|c|c|c|c|c|c|}
\hline \multirow[b]{3}{*}{ 1. Living arrangements } & \multicolumn{4}{|c|}{ first age group (60-80) } & \multicolumn{4}{|c|}{ second age group $(80+)$} & \multicolumn{4}{|c|}{ In total } \\
\hline & \multicolumn{2}{|c|}{ Female } & \multicolumn{2}{|c|}{ Male } & \multicolumn{2}{|c|}{ Female } & \multicolumn{2}{|c|}{ Male } & \multicolumn{2}{|c|}{ Female } & \multicolumn{2}{|c|}{ Male } \\
\hline & $\mathrm{n}$ & $\%$ & $\mathrm{n}$ & $\%$ & $\mathrm{n}$ & $\%$ & $\mathrm{n}$ & $\%$ & $\mathrm{n}$ & $\%$ & $\mathrm{n}$ & $\%$ \\
\hline Living alone & - & $\mathbf{0}$ & - & $\mathbf{0}$ & - & $\mathbf{0}$ & - & $\mathbf{0}$ & - & $\mathbf{0}$ & - & $\mathbf{0}$ \\
\hline Living with others & - & $\mathbf{0}$ & - & $\mathbf{0}$ & - & $\mathbf{0}$ & - & $\mathbf{0}$ & - & $\mathbf{0}$ & - & $\mathbf{0}$ \\
\hline $\begin{array}{l}\begin{array}{l}\text { Living in } \\
\text { homes }\end{array} \\
\text { nursing }\end{array}$ & 26 & 61,9 & 16 & 38,1 & 17 & 61 & 11 & 39 & 43 & 61,4 & 27 & 38,6 \\
\hline \multicolumn{13}{|l|}{ 2. Marital status } \\
\hline Single & 2 & 4,8 & - & $\mathbf{0}$ & 1 & 3,6 & - & $\mathbf{0}$ & 3 & 4,3 & - & $\mathbf{0}$ \\
\hline Married & 11 & 26,2 & 10 & 23,8 & 1 & 3,6 & 4 & 14,3 & 12 & 17,1 & 14 & 20 \\
\hline Widowed & 6 & 14,3 & 3 & 7,1 & 15 & $\mathbf{5 3 , 5}$ & 6 & 21,4 & 21 & 30 & 9 & 12,9 \\
\hline Divorced & 7 & 16,7 & 3 & 7,1 & - & $\mathbf{0}$ & 1 & 3,6 & 7 & 10 & 4 & 5,7 \\
\hline Non-marital partnership & - & $\mathbf{0}$ & - & $\mathbf{0}$ & - & $\mathbf{0}$ & - & $\mathbf{0}$ & - & $\mathbf{0}$ & - & $\mathbf{0}$ \\
\hline \multicolumn{13}{|l|}{ 3. Education } \\
\hline High school education & 11 & 26,2 & 11 & 26,2 & 8 & 29 & 7 & 25 & 19 & 27,1 & 18 & 25,7 \\
\hline Secondary school education & 14 & 33,3 & 5 & 11,9 & 9 & 32 & 4 & 14 & 23 & 32,9 & 9 & 12,9 \\
\hline Illiterate & 1 & 2,4 & - & $\mathbf{0}$ & - & $\mathbf{0}$ & - & $\mathbf{0}$ & 1 & 1,4 & - & $\mathbf{0}$ \\
\hline \multicolumn{13}{|l|}{ 4. Subjective health } \\
\hline Excellent & 1 & 2,4 & - & $\mathbf{0}$ & 1 & 3,6 & - & $\mathbf{0}$ & 2 & 2,9 & - & $\mathbf{0}$ \\
\hline Very good & 1 & 2,4 & - & $\mathbf{0}$ & 1 & 3,6 & - & $\mathbf{0}$ & 2 & 2,9 & - & $\mathbf{0}$ \\
\hline Good & 7 & 16,7 & 3 & 7,1 & - & $\mathbf{0}$ & $\mathbf{1}$ & 3,6 & 7 & 10 & 4 & 5,7 \\
\hline Fair & 8 & 19 & 8 & 19 & 6 & 21,4 & 3 & 10,7 & 14 & 20 & 11 & 15,7 \\
\hline Fair & 9 & 21,4 & 5 & 12 & 9 & 32,1 & 7 & 25 & 18 & 25,7 & 12 & 17,1 \\
\hline
\end{tabular}

Education: By this parameter, the survey group showed that more than half of the respondents (52.8\%) have higher education (higher or technical), and almost half of them have finished the school (45.8\%). 
Only one female was not able to read and write; the people with the highest education were in equal number in both sexes.

Subjective health: We have set this query with the standard questions asked in the questionnaire: "How do you feel? What do you think about your health condition?" Most of the respondents estimated their health condition as satisfactory and bad. The assessment "good" was reported by 11 (26\%), a "very good" - by two beneficiaries, "excellent" - also by two beneficiaries, it should be mentioned that last two, the most positive respondents were women.

Most of the respondents in the first age group evaluated their health condition as a "satisfactory" and "bad" - 71.5\%. A "good" and "very good" assessment was made by a quarter of respondents, most of them were women. In the second age group, more respondents fixed the assessment "bad" comparing to the first group. However, despite biological age, 7.2\% feel "good" or "very good", while one person evaluated his health as an "excellent".

Cognitive disorders were revealed in $40 \%$ of individuals. Dementia was found in $44,3 \%$ of respondents (20 women and 11 men), And without dementia - 35.7\%. In addition, people with dementia are equally divided into first and second age groups (Tab. 2). It is noteworthy that the oldest people from the second age group did not show severe cognitive status and dementia, which once again proves that biological age is not a definitive determinant of human cognitive status and it is quite possible that a very old person was mentally healthy [18].

Table 2. Cognitive status and dementia index in the study population

\begin{tabular}{|l|l|l|l|l|l|l|l|l|l|l|l|l|l|l|}
\hline & \multicolumn{9}{|l|}{ first age group (60-80) } & \multicolumn{3}{l|}{ second age group (80+) } & \multicolumn{2}{l|}{ In total } \\
\hline Cognitive status & Female & \multicolumn{2}{l|}{ Male } & \multicolumn{2}{|l|}{ Female } & \multicolumn{2}{l|}{ Male } & \multicolumn{2}{|l|}{ Female } & \multicolumn{2}{|l|}{ Male } \\
\hline & $\mathrm{n}$ & $\%$ & $\mathrm{n}$ & $\%$ & $\mathrm{n}$ & $\%$ & $\mathrm{n}$ & $\%$ & $\mathrm{n}$ & $\%$ & $\mathrm{n}$ & $\%$ \\
\hline Severe (0-17) & 8 & 19,1 & 5 & 11,9 & 9 & 32 & 6 & 21,4 & 17 & 24,3 & 11 & 15,7 \\
\hline Moderate (18-23) & 7 & 16,6 & 3 & 7,1 & 4 & 14,3 & 2 & 7,1 & 11 & 15,7 & 5 & 7,2 \\
\hline Mild (24-30) & 11 & 26,2 & 8 & 19,1 & 4 & 14,3 & 3 & 10,7 & 15 & 21,4 & 11 & 15,7 \\
\hline Dementia & & & & & & & & & & & \\
\hline $\begin{array}{l}\text { Dementia stages (0- } \\
\text { 21) }\end{array}$ & 10 & 23,8 & 5 & 11,9 & 10 & 35,7 & 6 & 21,4 & 20 & 28,6 & 11 & 15,7 \\
\hline $\begin{array}{l}\text { Pre-dementia stages } \\
(21-24)\end{array}$ & 5 & 11,9 & 4 & 9,5 & 3 & 10,7 & 2 & 7,2 & 8 & 11,4 & 6 & 8,6 \\
\hline $\begin{array}{l}\text { Without dementia } \\
\text { stages (25-30) }\end{array}$ & 11 & 26,2 & 7 & 16,7 & 4 & 14,3 & 3 & 10,7 & 15 & 21,4 & 10 & 14,3 \\
\hline
\end{tabular}

From the defining criteria of the frailty syndrome (Tab. 3), the three most common criteria in our study population were: low physical activity, loss of power and slowing down movement. Based on the analysis of the data obtained, $25.7 \%$ of the researched population is frailty phenotype, $12,9 \%$ prefrail phenotype, $61.4 \%$ - healthy or sustainable. There were 18 individuals in total with frailty, including 11 women and 7 males. 
Table 3. Frailty dissemination in the study population

\begin{tabular}{|c|c|c|c|c|c|c|c|c|c|c|c|c|}
\hline & \multicolumn{4}{|c|}{ first age group (60-80) } & \multicolumn{4}{|c|}{ second age group $(80+)$} & \multicolumn{4}{|c|}{ In total } \\
\hline & \multicolumn{2}{|c|}{ Female } & \multicolumn{2}{|c|}{ Male } & \multicolumn{2}{|c|}{ Female } & \multicolumn{2}{|c|}{ Male } & \multicolumn{2}{|c|}{ Female } & \multicolumn{2}{|c|}{ Male } \\
\hline & $\mathrm{n}$ & $\%$ & $\mathrm{n}$ & $\%$ & $\mathrm{n}$ & $\%$ & $\mathrm{n}$ & $\%$ & $\mathrm{n}$ & $\%$ & $\mathrm{n}$ & $\%$ \\
\hline Weight loss & 6 & 14,3 & 1 & 2,4 & 5 & 17,9 & 2 & 7,1 & 11 & 15,7 & 3 & 4,3 \\
\hline Weakness & 4 & 9,5 & 2 & 4,8 & 7 & 25,0 & 5 & 17,9 & 11 & 15,7 & 7 & 10,0 \\
\hline Exhaustion & 3 & 7,1 & 2 & 4,8 & 4 & 14,3 & 4 & 14,3 & 7 & 10,0 & 6 & 8,6 \\
\hline Slowness & - & 0,0 & 3 & 7,1 & 9 & 32,1 & 7 & 25,0 & 9 & 12,9 & 10 & 14,3 \\
\hline Low physical activity & 4 & 9,5 & 3 & 7,1 & 8 & 28,6 & 6 & 21,4 & 12 & 17,1 & 9 & 12,9 \\
\hline 0 criteria & 20 & 47,6 & 12 & 28,6 & 7 & 25,0 & 4 & 14,3 & 27 & 38,6 & 16 & 22,9 \\
\hline 1 criterion & 1 & 2,4 & 1 & 2,4 & 1 & 3,6 & & 0,0 & 2 & 2,9 & 1 & 1,4 \\
\hline 2 criteria & - & 0,0 & - & 0,0 & 3 & 10,7 & 3 & 10,7 & 3 & 4,3 & 3 & 4,3 \\
\hline 3 criteria & 4 & 9,5 & 2 & 4,8 & - & 0,0 & - & 0,0 & 4 & 5,7 & 2 & 2,9 \\
\hline 4 criteria & 1 & 2,4 & 1 & 2,4 & 4 & 14,3 & 2 & 7,1 & 5 & 7,1 & 3 & 4,3 \\
\hline 5 criteria & - & 0,0 & - & 0,0 & 2 & 7,1 & 2 & 7,1 & 2 & 2,9 & 2 & 2,9 \\
\hline
\end{tabular}

According to the obtained results, frailty syndrome is higher in the group of people over 80 years (35.7\%) than in the first age group (19\%). As we see, the frailty syndrome is correlated with age, the more the biological age of the age group, the more frailty phenotype can be found. The obtained data coincides with the findings of other European populations [8]. We could not find a significant difference in sexes.

The researchers often refer to cognitive disorders and frailty connections [15]. In our case, only three individuals were found from 18 frailty phenotypes of severe cognitive disorder. Perhaps the relationship could not be revealed because of the lack of sample amount, and on the other hand, the features of the population should be taken into account as well.

\section{Conclusions and recommendations}

As the research has shown frailty syndrome is revealed in beneficiaries in both investigated groups. The spread of frailty in various age group in nursing homes requires the study of their physical condition. It is important to be assessed frailty syndrome in nursing community for timely medical and social assistance and other activities. Complex emerging programs would help beneficiaries to keep their independent daily activity and delay their disability.

\section{References}

[1] Wagner KH., Cameron-Smith D., Wessner B., Franzke B., "Biomarkers of Aging: From Function to Molecular Biology", Nutrients, 8(6), 338, 2016. doi: 10.3390/nu8060338.

[2] Xia X., Chen W., Dermott J. Mc., Jing-Dong Jackie Hana, "Molecular and phenotypic biomarkers of aging", REVIEW F1000Res., 6, 860, 2017. 
[3] Crimmins E., Vasunilashorn S., Kim JK, Alley D., "Biomarkers related to aging in human populations", Adv. Clin Chem., 46, 161-216, 2008.

[4] Hammadah M., Al Mheid I., Wilmot K., et al.: "Telomere Shortening, Regenerative Capacity, and Cardiovascular Outcomes", Circ Res, 120(7), 1130-1138, 2017. doi: 10.1161/CIRCRESAHA.

116.309421

[5] Khukhunaishvili R., Koridze M. et al., "Some Bio-gerontological Peculiarities of Long-livers in Ajara Region of Georgia", $19^{\text {th }}$ IAGG word congress of Gerontology and Geriatrics, Paris, France. The Journal of Nutrition, Health and Aging, 7, 54-58, 2009.

[6] Lang P.-O., Michel J.-P., Zekry D., "Frailty Syndrome: A Transitional State in a Dynamic Process", Gerontology, 55(5), 539-549, 2009.

[7] Fried LP., Tangen CM., Walston J., Newman AB., Hirsch C., Gottdiener J., et al. "Frailty in older adults: evidence for a phenotype", J Gerontol A BiolSci Med Sci, 56 (3), 146-56, 2001.

[8] Rockwood K., Song X., Mitnitski A., "Changes in relative fitness and frailty across the adult lifespan: evidence from the Canadian National Population Health Survey”, CMAJ, 183(8), 487-494, 2011.

[9] Santos-Eggimann B., Cuenoud P., Spagnoli J., Junod J., "Prevalence of frailty in middle-aged and older community-dwelling Europeans living in 10 countries", J Gerontol A Biol Sci Med Sci, 64(6), 675-681, 2009.

[10] Morley JE., Malmstrom TK., Miller DK., "A simple frailty questionnaire (FRAIL) Predicts outcomes in middle-aged africanamericans", J. Nutr Health Aging, 16(7), 601-608, 2012.

[11] Strandberg TE., Pitkala KH., Tilvis RS., "Frailty in older people", Eur Geriatr Med, 2(6), 344-355, 2011.

[12] DreyM., Pfeifer K., SieberC.C., Bauer J.M., "The Fried Frailty Criteria as Inclusion Criteria for a Randomized Controlled Trial: Personal Experience and Literature Review", Gerontology, 57(1), 11-18, 2011.

[13] Gill TM., Gahbauer EA., Allore HG., Han L., "Transitions between frailty states among community-living older persons", Archives of Internal Medicine, 166(4), 418-423, 2006.

[14] Fried LP., Tangen CM., Walston J., Newman AB., Hirsch C., Gottdiener J., Seeman T., Tracy R., Kop WJ., Burke G., McBurnie MA., "Cardiovascular Health Study Collaborative Research G. Frailty in older adults: evidence for a phenotype", J Gerontol A BiolSci Med Sci, 56(3), 146-156, 2001.

[15] Duarte N., Teixeira L., Ribeiro O. Paúl C., "Frailty phenotype criteria in centenarians: Findings from the Oporto", Centenarian Study, 5(6), 371-376, 2014. DOI: 10.1016/j.eurger.2014.09.015 [16] Folstein MF., Folstein SE., McHugh PR, "Mini-mental state: A practical method for grading the cognitive state of patients for the clinician", J Psychiatr Res, 12, 189-198, 1975.

[17] Fillenbaum GG., Smyer MA., "The development, validity, and reliability of the Oars

Multidimensional Functional Assessment Questionnaire”, Journal of Gerontology, 36(4), 428-434, 1981.

[18] Santos-Eggimann B., Cuenoud P., Spagnoli J., Junod J., "Prevalence of frailty in middle-aged and older community-dwelling Europeans living in 10 countries", J Gerontol A BiolSci Med Sci, 64(6), 675-81, 2009. 